\title{
INQUIETUDE ARTÍSTICA E EDUCATIVA DE UM INVESTIGADOR Ainda assim, por uma investigação implicada na construção de uma democracia agonistica
}

José Carlos de Paiva Universidade do Porto

A maior riqueza do homem

é a sua incompletude.

Nesse ponto sou abastado.

Palavras que me aceitam como sou - eu não aceito.

Não agüento ser apenas um sujeito que abre portas,

que puxa válvulas, que olha o relógio,

que compra pão às 6 horas da tarde,

que vai lá fora,

que aponta lápis,

que vê a uva etc. etc.

Perdoai

Mas eu preciso ser Outros.

Eu penso renovar o homem usando borboletas.

(Manoel de Barros) 


\section{Resumo}

A incerteza do sujeito, protagonista discreto da procura da sua lucidez, não mais mostra do que a angústia suscitada pela procura de um espaço adequado à percepção cultural do mundo contemporâneo e ao modo próprio de sociabilização do seu conhecimento. É na digestão da angústia e na narrativa da indignação que me desloco para dentro de mim, para a inserção em realidades Outras, para fora do tecido cosmopolita desfronteiralizado, complexo, desorientado, desunido, desiludido, para perto do irreverente, onde se procura um outro devir, um destino utópico, novas formas de participação democrática, outras escolas, outros modos de democratizar o exercício do político, de relacionamento humano solidário, de respeito cívico, de respeito pela natureza, ...

Métier de professor/artista/investigador.

Palavras-chave: educação artística, arte, investigação, intercultural

\section{Abstract}

The uncertainty of the individual, a discreet protagonist searching for his clarity, no longer shows the anxiety caused by the finding of a suitable space to the cultural perception of the contemporary world and the proper way of socialization of his knowledge.

It is in the digestion of anguish and of a narrative of indignation that I move inside me, for insertion into Other realities, out of the cosmopolitan territory without frontiers, complex, disoriented, disunited, disillusioned, close to the irreverent, where I try another becoming, a utopian destination, new forms of democratic participation, other schools, other ways to democratize the exercise of the political, of the human solidarity, of the respect civic, of the respect for nature, ...

$\mathrm{A} / \mathrm{R} / \mathrm{T}$ métier,...

keywords: arts education, art, research, intercultural 


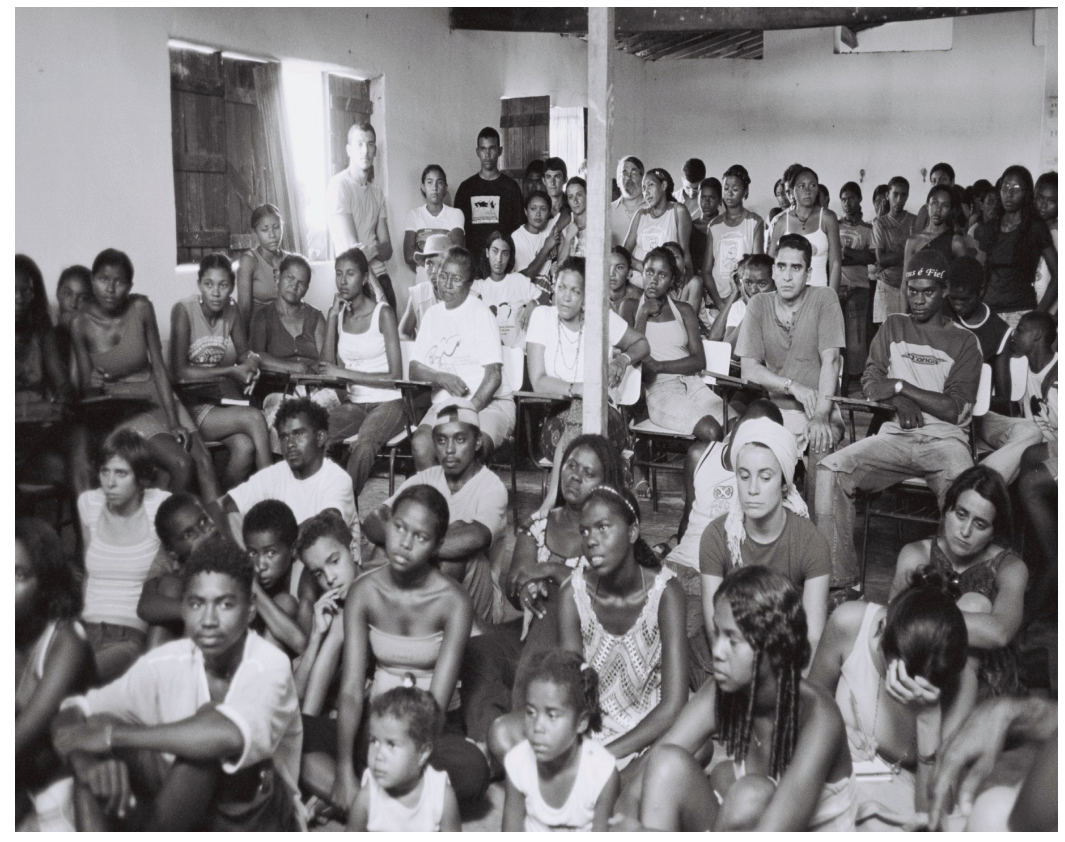

População de Conceição das Crioulas, Salgueiro-PE, assistindo ao primeiro documentário realizado pelo Crioulas Vídeo. Imagem de arquivo IDENTIDADES, 2005

\section{Cito CÉSAIRE, Aimé. (1955:69)}

Há uma lei de desumanização progressiva, em virtude de que, doravante, na ordem do dia da burguesia, há, e agora só pode haver, a violência, a corrupção e a barbárie.

Ia-me esquecendo do ódio, da mentira e da presunção.

Estou inquieto nas Universidades onde habito, insatisfeito com o modo como as epistemologias se constroem e as etimologias se estabelecem, no seu próprio fechamento, refúgio inócuo de imunidade, afastamento de vínculos de interferência no complexo da vida, esquecimento dos espaços bafientos que circundam e abundam e lhe deveriam inundar a missão.

O tempo, tornado ausente pelo espaço dilatado do dominante, que recusa outras possibilidades de circunstância perspéctica, que teme tudo o que estorve a facilidade especulativa, a ganância e o privilégio burguês, tempo congelado, como a vida dos que já não são produtivos, e foram tornados incómodos por quem não quer sentir o cheiro incomodativo de sua sobrevivência, mesmo assim, surpreendente e criativa.

A dificuldade de encontrar um espaço pregnante de resistência e de evidenciação agonística de outras possibilidades, essa dificuldade que convoca a noção de impotência, de produção artística relevante, de impossibilidade de acção educativa autónoma e de produção de pensamento controverso, afasta-me de mim, seca-me o devir de professor / 
artista /investigador, esgota o discernimento interventivo, a entrega ao ofício, o optimismo, semeia a inquietude.

A procura de satisfação dos interesses financeiros especulativos e dos monopólios globalizados pelos decisores políticos, desviam o ensino público para funções utilitaristas e eficazes na sustentação dos regimes sociais que inundam os continentes, onde os acordos governamentais de Bolonha são a evidência no espaço do ensino europeu e os resultados do 'desenvolvimento', num sentido geral, são um retrato objectivo da sua falência.

A mercantilização da sociedade, a especulação financeira, o logro da responsabilidade individual e do empreendedorismo, a espectacularização do social, a mediatização dos relacionamentos e o estrangulamento das possibilidades da lentidão, da contemplação, da profundidade, da atenção, regulam os sujeitos, e seduzem os artistas e os agentes culturais para a redoma das indústrias criativas, de onde organizam um espaço de consumo para os seus públicos. A espectacularidade desencadeia irrealidades, que se expandem e inundam, simulacros de realidade mediatizada.

A Universidade vê o seu espaço privilegiado desaparecer em conjunto com a desmaterialização dos Estado-Nação e sente-se tentada em assumir funções empresariais que perseguem a excelência produtiva. Tarda em se encontrar a possibilidade de ser um espaço Outro, contemporâneo, para se pensar de outra maneira, e de novo, a noção de comunidade, já não enquanto unidade coesa, mas como hipótese democrática de se ser-em-conjuto e de se relacionar não como instituição modelar, mas numa pertença agonística, mas equivalente ao todo.

A 'educação artística', espaço sempre promissor de resiliência e produção de realidade, confina-se a um campo tolerado de promoção de generalidades, de genialidades e de espaços de remissão compensatória e de salvação do eu, desarientada e fixada no seu próprio passado, desejado.

Esta inquietude, de que escrevo, que se instala em boa parte dos sujeitos que se entendem como críticos na universidade, não me anula o optimismo, conhecedor que sou de muitas lutas, participante em resistências, positivo e armado da consciência da impossibilidade, mas resiliente perante o adverso. Nesta angústia optimista me apresento. É a este lugar ambivalente e impertinente que pertenço. Não quero ser governado pelo hegemónico, e por isso procuro a arte que me promova ao estado da crítica, do político, estado de procura de um aberto para o que há-de vir.

A força eurocêntrica do conhecimento e da tradição que me funda, facilita-me o discernimento crítico sobre o beco hipócrita que habito, que me funda, e obriga-me a procurar outros ares para respirar, para confrontar realidades, para saber o que esqueci das memórias biológicas da humanidade, para aprender a ser. Retomo o ensinamento do pintor que nunca ignora a necessidade de afastamento para melhor enxergar o que faz, lonjura que o impele a ler as insuficiências do feito.

Afastamento que é uma tentativa de entender as gananciosas economias 'submergentes' do Ocidente, que algemam o futuro e tentam toldar o olhar em frente, esforço de 
uma viagem que permite olhar para trás, e ver, a partir das acções renovadas das sociedades 'emergentes', o que se experiencia, no artístico, no educativo, na investigação, nas ruas, onde o político afronta os domínios hegemónicos e a cegueira das políticas cegas do capital financeiro, e onde ainda se conhecem realidades.

\section{Cito APPADURAI, Arjum. (1966:251)}

Em termos simples, a tarefa de produzir localidade (como uma estrutura de sentimento, uma propriedade da vida social e uma ideologia de comunidade situada) é cada vez mais uma luta.

É assim que saio de casa, parto, constantemente, em busca de sentires outros, para respirar a brisa ainda fresca que se espalha em outras geografias, para cheirar a terra e pisar o mesmo chão dos autores que viveram comigo ao longo de meu crescimento e me possibilitaram moldar a minha consciência e o meu corpo. Destinos africanos percorro, e o Nordeste do Brasil. Proximidades. Deslocações.

Retomo no Nordeste do Brasil, as representações conhecidas, que o êxito alcançado na minha juventude pelo novo cinema brasileiro, do censurado filme "Rio $40^{\circ}$ " (1955), de Nelson Pereira dos Santos e a difusão nos meios cine-clubistas dos filmes de Glauber Rocha, "Deus e o diabo na terra do sol” (1963) e "Terra em transe” (1967). Releio os livros devorados e partilhados às escondidas da repressão da ditadura salazarista, de Guimarães Rosa, Gilberto Freyre, Graciliano Ramos, João Cabral de Mello Neto, Jorge Amado, José Lins do Rego, Josué de Castro, Manuel Bandeira e Rachel de Queiroz, e sinto o mesmo sentimento de solidariedade para com as lutas do povo nordestino. Ouço de novo minha mãe trauteando Zélia Barbosa e outros sertões e favelas se me apresentam.

Retomo as conversas em directo com Givan Samico, Paulo Brunski, Givânia Silva, Ariano Suassuna, Pedro Américo de Farias, Roberto Benjamin, Marcelo Mário de Melo, Silvana Meireles, e tentas centenas de saberes, completamente por ouvir.

Durmo em casa de amigos e de amigas, toco, frequento os debates e eventos públicos, entranho-me.

Cheguei a um Brasil já outro, afastado da ditadura, mais fresco e confiante, repleto de movimentos sociais e de acções culturais construtoras de uma outra realidade social, que prolongam as lutas contra a pobreza, a prepotência senhorial dos fazendeiros, coronéis e políticos corruptos. A presença da memória, dos movimentos contra a escravatura, da fuga rebelde de um grupo de escravos para o Quilombo dos Palmares, mistura-se com as vivências, com as conflitualidades urbanas do Recife e de suas periferias, onde mergulho.

Com essa ânsia envolvi-me em eventos que tornaram o Nordeste também meu, 
onde partilhei minhas apreensões, e encontrei lugar.

Inteirei-me das utopias, tornei-me cúmplice de instituições, impliquei-me em dinâmicas locais das populações, na promoção de melhor educação e escola, outras vidas e do desenvolvimento.

Tornei-me o que sou. Apenas.

\section{Cito NABUC0, Joaquim. (1884:95)}

Não há, senhores, no mundo inteiro atualmente um ponto onde se esteja realizando uma obra maior, mais universal, mais cheia de interesse para a humanidade do que a que empreendemos no Brasil em favor da liberdade de um milhão e quinhentos mil escravos.

Por sorte fui parar ao sertão, pela mão da professora Delma Silva, então do Centro de Cultura Luíz Freyre, de Olinda. Com um grupo de estudantes, artistas e professores (movimento intercultural IDENTIDADES) entrámos na vida de uma pequena comunidade quilombola, longe dos núcleos urbanos, e finalmente entendi, de facto, o que significa uma 'economia de subsistência' e a profundidade da 'solidariedade' que se espalha nesses territórios inóspitos, de caatinga e seca. Em parceria entrei numa 'comunidade' e tornei-me lutador de seus desejos e cúmplice de seus sonhos e planos.

A abolição oficial da escravatura (13 de maio de 1888) não alterou as privações desta comunidade negra, misturada com a indígena, que privada de suas propriedades faz da luta pela propriedade colectiva da terra o centro de sua resistência. Sentado numa sombra, com a memória de 'À sombra desta mangueira' de Freire (2006), li o artigo assinado pelo Presidente Lula (68/ADCT/ CF1998) que refere que "aos remanescentes das comunidades de quilombos que estejam ocupando suas terras, é reconhecida a propriedade definitiva, devendo o Estado emitir-lhes títulos respectivos", e vivenciei a distância que separa a lei da sua concretização, e a força dos antigos coronéis que perdura. E entendi o envolvimento da educação na consolidação da consciência que tornou partilhada a persistência de onde resultou já a recuperação 'no papel' de um 'pedaço de chão' pela comunidade.

São quase oitocentas as Comunidades Quilombolas registadas pela Fundação Palmares do Ministério da Cultura (1999) de um universo que se estima em cerca de três mil. Por sorte minha e dos estudantes, professores e artistas (movimento intercultural IDENTIDADES), que integram estas deslocações por África e pela América Latina, verdadeiramente para dentro de cada um de nós, fomos ter a Conceição das Crioulas (Salgueiro-PE), onde a exemplaridade social e cultural é patente e o discernimento político é impressionantemente lúcido.

A sorte levou-me e levou-nos lá. Nenhuma semelhança com o que partilháramos em Moçambique ou em Cabo Verde ou em outros paradeiros, tão distintos eram 
os contextos, tão fecundas as possibilidades de um relacionamento com a comunidade e tão atraente e complexa a sua dinâmica social. Ainda hoje a memória sabe o quanto desorientados nos sentíamos, qual o enamoramento que se teceu entre todos, apenas a partir do primeiro encontro, dos olhares e dos abraços de corpos unidos.

Mais de uma década de deslocações para o interior do Sertão, de participação de professores e jovens da comunidade em acções em Cabo Verde e em Portugal, aprende-se o crescimento deste povo, as conquistas que se vão registando, a maturidade das mulheres que assumem a liderança, a resistência persistente ao infortúnio, o crescimento do escolar e a desescolarização dos saberes. Também as contradições, as contrariedades, a insuficiência. Ou conquistas de linguagens, como a do vídeo que passou a fazer parte da sua luta. A educação artística que passou a integrar os currículos nas escolas, a revitalização dos fazeres ancestrais, a extensão do uso da internet, ...

O sua identidade constrói-se nesse processo de sobrevivência e resistência, numa escola sem separação alguma do que é comum, na autonomia de seu modo de colectivizar a presença, de articular os 'sítios', no reforço da unidade e na capacidade de organização político/administrativa.

A consciência política para que seja feita justiça e se proceda à retomada das terras é o objectivo central da sua Associação Quilombola de Conceição das Crioulas (2000), e a primeira grande vitória, com a inscrição em lei do primeiro 'pedaço de chão' como propriedade da comunidade, anima.

\section{Cito READINGS, Bill. (1996:28)}

Mais do que em questões de conteúdo, a força transgressora do ensino reside na forma como a pedagogia pode manter em aberto a temporalidade do questionamento, de modo a resistir a ser caracterizada como uma transacção que é dada por terminada pela atribuição quer de notas quer de disciplinas.

Este texto, onde me desnudo, pretende-se preso aos processos onde a liberdade com que minha consciência e sensibilidade gere as angústias que o contexto das universidades por onde circulo, em que meu trabalho quotidiano com os estudantes, em minha investigação, se confrontam. São corpos ambivalentes, com tanto de reguladores e de castradores como de desafiantes a se ocuparem as 'falhas', a percorrer as brechas por onde o dispositivo das academias ainda permite agir, no agonístico e no antagónico.

Precisa-se de professores que pensem com os seus estudantes, e com os seus pares, o que não é ainda claro e evidente, o que se esconde atrás da força dos modelos de classificação e de organização escolar, na sombra dos programas e dos objectivos definidos, na outra face da procura de sucesso, que pensem e denunciem a ideia naturalizada desde o iluminismo da salvação da humanidade pela educação estruturada, e servidora dos de- 
sígnios determinados de bons-cidadãos dos Estados/Nação existentes ou em construção.

Hoje, quando a governação se globaliza e se afasta dos governos 'democráticos' para instâncias supranacionais, obrigando a se procurarem outras formas de democracia, participativa e radical, é mais que urgente promover espaços de discussão com inserção no local, com âncoras nas realidades das populações e em seus problemas, para aí se discernirem as amarras dos sujeitos, as suas impotências, as possibilidades dessa consciência despertar o porvir. E agir.

Precisa-se de professores que pensem com os seus estudantes o que não é compreendido e mesmo o que estes não procuram saber, para que se torne possível fazer o que não foi feito ainda. É preciso passar pela incomodidade do corpo que pretende ocupar um espaço que não está livre. E agir.

Em Conceição das Crioulas, e também na comunidade de Lagedos e no Planalto Norte, na ilha de Santo Antão em Cabo Verde, é possível ver uma população conhecedora que a escola cria possibilidades outras de se construírem identidades, abertas ao mundo, mas intervenientes no seu sítio, molhadas nas suas memórias, conhecedoras da persistência e sofrimento das lutas havidas, das contrariedades existentes. Partilhar estas realidades, é também entender como é importante desnudar a universidade da excelência e da eficácia, expor os simulacros onde esconde sua rotina de promover a liberdade dos sujeitos', sem esclarecer os limites onde a prende, a submissão ao hegemónico, ao conforto do já conhecido.

Este conhecimento confere-me, nas universidades onde habito, a irresponsabilidade de me saber com um entendimento antagónico com o reinante, com uma prática agonística na procura de consensos possíveis, na teimosia da não desistência. Esse conhecimento torna prioridade a sua presença nas relações educativas promovidas com os estudantes.

Naquelas comunidades, nenhuma auto-satisfação me salva da inquitude, tal é a proximidade ao persistente sofrimento diário e à perseverança das gentes que orgulhosamente conheço. Deslocado me sinto, nessa pertença, na identificação do chão que os pés-descalços verificam já, mas a responsabilidade na construção dos sujeitos que acompanho está solta pela mesma-coisa que são a escola e a saúde, a luta pela terra e o património, o pão e o chão, o um e o todos.

\section{Cito MOUFFE, Chantall. (2007:18)}

Lo político tiene que ver con la dimensión del antagonismo presente en las relaciones sociales, con la posibilidad siempre presente de que la relación 'nosotros/ellos' se construya en términos de 'amigo/enemigo'. 
As universidades medievalistas da velha Europa, fechadas nos seus saberes e guardiãs do conhecimento do passado e do sagrado, as academias elitistas e elitizantes do iluminismo, e mesmo as escolas do modernismo e as universidades do século passado, ainda ocupam demasiada presença no campo das instituições educativas do século XXI, que tardam em se entenderem nesta sociedade contemporânea, onde se vão tornando instituições desligadas dos Estado-Nação, se autonomizam e apenas buscam lugar nos ranking da "excelência".

Este caminho enfraquece o espaço da investigação nas áreas classificadas como menos produtivas para a elevação dos lucros de produção, a ampliação desenfreada de um consumo que não é só de bens de necessidade e de ostentação, mas do próprio saber, ou que menos contribuem para alimentar o sistema de especulação financeira e de transformação de tudo nos seus simulacros, da própria sedução ao crime. A filosofia, a arte, a sociologia e outras áreas científicas são remetidas para uma excepcionalidade rareada.

O espaço para a investigação em arte, como para a investigação em educação artística, enquanto processos interventivos e possibilitadores do desenvolvimento de posturas críticas de sujeitos conscientes, no contexto das políticas ultra-liberais hegemónicas, tem de ser conquistado, nas universidades e nos lugares de acção social, onde a sua expressão produtiva tem cabimento e carência.

É este trânsito, entre uma inclusão agonística na universidade, na vida académica, no relacionamento educativo com os estudantes, e a expansão da actividade que promove para as tensões que comunidades enfrentam, que se procura um lugar e um devir para a investigação, que se desliga da procura epistemológica de interpretações eruditas do mundo, para uma relação intensa da acção com a investigação, da produção artística com o seu eco e a sombra que se produz. A Arte sempre foi uma materialidade. Nela se situa a essência da educação artística.

A angústia do tempo anuncia a urgência de uma acção persistente em busca de uma narrativa renovada, da construção pertinaz de uma democracia Outra, que permita e promova acções educativas e artísticas implicadas, que possibilitem aos que hão-de vir, a construção de suas vidas sociais, a construção das representações próprias de cada sujeito, e não lhe determine e pré-configure o sentido de existência.

Sabe-se isso frequentando o Sertão não urbanizado. Lendo o que lá se passa, nos silêncios prolongados dos mais velhos, no olhar quente da juventude, nos sorrisos das crianças. A sua insistência, dificilmente compreendida por quem não imagina sequer o sofrimento calado e superado que atravessa a sua história, é essa lição, simples...

E agir... 


\section{Cito FREIRE, Paulo. (1966:97)}

\section{(...) arte, pesquisa e ensino não são feitos, mas vividos.}

Uso esta designação de 'educação artística' para determinar um campo epistemológico e deontológico singular, onde se efectivam práticas educativas multidisciplinares (e não no espaço restrito das artes visuais ou das artes plásticas), no ensino formal e não-formal, nos museus, instituições e centros culturais, nos espaços de mediação e onde se estabeleçam relacionamentos críticos com a arte como o seu cerne. E no mesmo sentido refiro a investigação que se efectiva nesta ampla superfície de 'investigação em educação artística' distinguindo-a da investigação que faz sobre a arte (nessa exterioridade) e o mesmo sobre o ensino artístico.

Anulem-se os tiques disciplinares de isolamento dos saberes, iniba-se a tendência para a tradução do intradutível, assuma-se a sua própria obsolescência.

Foi longo o percurso para a conquista deste espaço de autonomia, para se manterem abertas as algemas metodológicas das 'ciências', mesmo das 'ciências da arte' e das 'ciências da educação'. É tempo para se assumirem as linguagens que são pertença do artístico para lhes encontrar o lugar inequívoco das suas possibilidades imanentes, da diferença de consentimento perante o indizível e o irrepetível, a excepção, o não justificável e o erro, a irreverência e a insubordinação.

A investigação em educação artística resulta de uma determinação de quem a habita em busca de um conhecimento crítico perante os redutores e naturalizados discursos que se difundem, uma ocupação de território particular de entendimento implicado na arte e na acção educativa e cultural, uma produção de conhecimento e de realidade.

\section{Cito HALL, Edward T.. (1983:105)}

Mas quase cinquenta anos de experiência de culturas de complexidades extremamente diversas convenceram-me de que o Ocidente cometeu um grande erro ao recusar considerar os conhecimentos e capacidades muito particulares desenvolvidos noutras culturas, apenas porque elas não são conformes aos nossos modelos científicos. Temos muito a aprender do estudo das outras culturas.

Uma investigação sem luvas e sem máscaras, a implicação de um artista numa paisagem frequentada por entidades singulares e por desígnios partilhados, que se convoca pleno, artista/professor, político inquieto, na procura de ser contaminado pela realidade a que sabe pertencer como contraponto das amarras académicas que o retem. 
Numa das primeiras deslocações efectuadas por uma equipa do IDENTIDADES a Conceição das Crioulas deparou-se-nos um problema simples. Para participar numa primeira oficina de vídeo que iríamos realizar a pedido da comunidade, estavam à nossa espera doze pessoas. O equipamento que transportávamos (nossa oferta) consistia num computador, uma câmara de vídeo, um microfone e respectivos cabos. A duração prevista da oficina seria de nove dias. Facilmente se percebeu que, para a oficina resultar e os participantes adquirirem autonomia na utilização da tecnologia e das lin-guagens, o grupo teria de ser reduzido, pelo menos, para metade. Colocava-se a questão de identificar quem seriam os seis jovens escolhidos para frequentar o pequeno curso. A escolha foi realizada numa discussão aberta e participada por todos, sem dramas e em plena democracia. Nem as responsáveis da associação (AQCC) presentes forneceram qualquer indicação na escolha. O resultado da escolha responsabilizou os par-ticipantes na oficina perante a população e o grupo empenhou-se afincadamente na aprendizagem, tendo obtido um inegável sucesso.

O grupo do IDENTIDADES assistiu incrédulo à utilização de um método simples na resolução de um problema - a democracia participativa. Foi uma das primeiras lições de democracia que recebemos em pleno sertão. Não mais deixámos de presenciar o envolvimento da população nas decisões da comunidade e certificámo-nos, em momentos especiais e no quotidiano, como este processo eticamente atraente resulta em envolvimento da população na resolução dos seus problemas e em unidade da comunidade. PAIVA, José Carlos de (2009:153)

\section{8. cito, para fechar AGAMBEN, Giorgio. Nidità (2009:17).}

(...) o conhecimento supremo é o que chega tarde de mais, quando já não serve.

\section{Referências bibliográficas:}

AGAMBEN, Giorgio. Nidità (2009). Nudez, Relógio D’Água (2010), tradução de Miguel Serras Pereira.

APPADURAI, Arjum. (1966). Modernity at Large - Culture Dimensions of Globalization. Dimensões Culturais da Globalização, Editorial Teorema (2004), tradução de Telma Costa. 
CÉSAIRE, Aimé. (1955). Discours sur le colonialisme, in Arte e Revolução, Abril e Maio (2005).

FREIRE, Paulo (1996). Pedagogia do Oprimido, Paz e Terra (2004).

FREIRE, Paulo (2001). À Sombra desta mangueira, São Paulo, Olho D’água, 2001.

HALL, Edward T. (1983). The Dance of Life - The Other Dimension of Time. A Dança da Vida - A Outra Dimensão do Tempo, Relógio D’Água (1996), tradução de Manuel Alberto.

MOUFFE, Chantal. Prácticas artísticas y democracia agonística (2007). Universidade Autónoma de Barcelona.

NÓVOA, António (1991). As Ciências da Educação e os Processos de Mudança, in AAAA, Ciências da Educação e Mudança, Porto, Sociedade Portuguesa de Ciências da Educação (1991).

NABUCO, Joaquim (1884), Terceira Conferência no Teatro Santa Isabel, a 16 de Novembro, in CAMPANHA ABOLICIONISTA NO RECIFE [ELEIÇÕES DE 1884], Edições do Senado Federal - Vol. 59 - Brasília - 2005, p. 95

PAIVA, José Carlos de (2009) Arte/desEnvolvimento, Porto: Faculdade de Belas Artes, Tese de Doutoramento.

READINGS, BILL (1996). The University in Ruins. A Universidade em Ruínas. Editora Angelus Novus, Coimbra (2003). 